\title{
Dinamization of Covid 19 Epidemic Control Program in Indonesia
}

\section{Cicilia Windiyaningsih*, Masdalina Pane, Aulia, Miftah, Dihram, Seweit Hotroiman and Ignatius Erik Sapta Yanuar}

Indonesian Epidemiologist Association, Student Faculty Public Health University

Indonesia, NIHRD, University of Defence Indonesia, Indonesia

*Corresponding Author: Cicilia Windiyaningsih, Indonesian Epidemiologist Association, Student Faculty Public Health University Indonesia, NIHRD, University of Defence Indonesia, Indonesia.
Received: December 02, 2020

Published: March 19, 2021

(C) All rights are reserved by Cicilia

Windiyaningsih., et al.

\begin{abstract}
Since the initial cases were announced by President Joko Widodo on March 2, 2020, it has been eight months since the Covid 19 pandemic in Indonesia took place, the number of confirmed cases up to October 42020 was 291,182 cases (14.38\%) of the total number of people examined 2,023,990 people, died positive for Covid 19 a total of 10,856(CFR 3.7\% from 10,856 divided into 291.182 cases) [1]. CFR is Case fatality rate until now there has not decreased of the end of the epidemic. Many countries have shown a decrease in cases, even some have started and have entered the second wave but are under control.
\end{abstract}

Keywords: Covid 19; Indonesia; Case Fatality Rate (CFR)

\section{Introduction}

Of the 10 countries with the largest population in the world, only Indonesia and India have not shown a decrease in the number of cases, but India's Case Fatality Rate is low (1.7\%), so pila with 11 WHO-SEARO (South East Asia Regional Office) countries only Indonesia and uncontrolled India. Global Case Fatality Rate $3.26 \%$, CFR Southeast Asia 1.8\%, even the Philippines which has the most cases has shown a decrease in cases in the past month with a CFR of 1.6\% [2]. Covid 19 has not been controlled in Indonesia, thousands of health workers have been infected with Covid 19 and hundreds of doctors and nurses have died. The essence of control is proper and fast containment through correct contact tracing through quality epidemiological investigations, conducting immediate and disciplined isolation and quarantine of affected areas.

\section{Methods}

The research objective analysis epidemic control program in Indonesia. analyzing the global situation as comparison to na- tional and local regions (8 provinces with the highest number of cases) and being aware of several provinces at risk of increasing cases of descriptive analysis and simple linear regression analysis for prediction by excel, epi esteem for epi contact. This Research used applied research methods, The data used in this research was published secondary data by Ministry of Health Republic Indonesia and comparative with studies on the conditions of Covid 19 control program in several countries, literature studies, journal, focus group discussions in several provinces and districts/cities such as: Aceh, West Sumatra, West Java, Lampung, Bengkulu, and South Kalimantan provinces. Control indicators such as Public Health Measure: $100 \%$ of the population uses masks; All public facilities provide hand sanitizers; All public facilities carry out physical distancing in all activities; Every health worker in health facilities uses level 1 PPE. Epidemiological indicators and health care systems in controlling Covid 19: Epidemiological indicators: Decrease in daily cases, positive rate, $80 \%$ of epi contact cases ( 2 consecutive weeks of significant decline. Death number of health worker (CFR) [3]. 
Results of Control program Covid 19 In the World as of 19 October 2020

The results of Covid 19 Control in 10 countries with the most population in the world as of October 19, 2020 in Chart of Daily Cases of 10 Countries with most populations in the world in 19 October 2020, as follows:

The situation of Covid 19 in the ten most populous countries such as New Cases in China 17493 cases (2020.02.16), India 97894 cases (2020.09.17), USA 75821 cases (2020.07.17), Indonesia 4850 cases (2020.10.08), Brazil 69074 cases (2020.07.29), Nigeria 1077 cases (2020.06.17), Bangladesh 4019 cases (2020.07.02), Russia 15150 cases (2020.10.16), Mexico 28115 cases (2020.10.15). The highest number of new cases reported in India, USA, Mexico, China and Russia> 10,000 new cases daily. The graph of the situation can be seen as follows in Chart below.

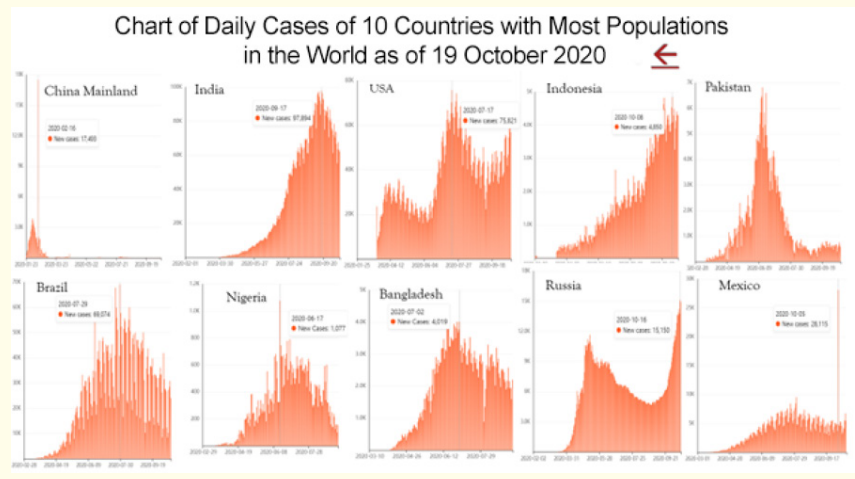

Chart 1

Chart Daily Case in SEARO in 19 October 2020 was follows in South East Asia as of October 19, the highest reported daily cases on 19 October 2020 such as: in India 46.498 cases (2020.010.19), Sri Lanka 87 cases (2020.10.19), Nepal 3.790 cases (2020.10.19), Bangladesh 1,637 cases (2020.10,19 Indonesia 3.373 cases (2020.10.19), Myanmar 1.180 cases (2020.10.19), South Korea 1.053 cases (2020.10.19), Maldives 22 cases (2020.10.19), Thailand 5 cases (2020.10.19), Bhutan 2 cases (2020.10.19), see below the Chart. https://www.worldometers.info/coronavirus/country/ Indonesia, India, Bangladesh, Thailand, South Korea, Myanmar, Bhutan, Maldives, Nepal, Sri Lanka [4].

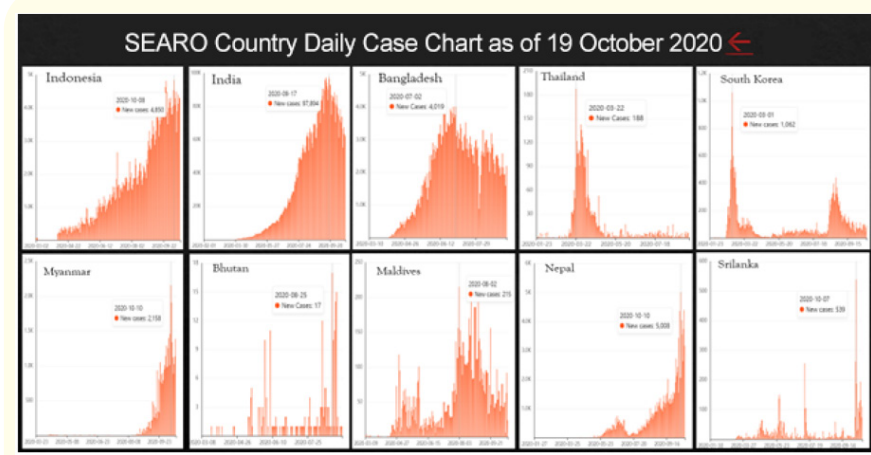

Chart 2

Daily cases in South East Asia

Chart 3 was reported daily cases : in Southeast Asia up to 19 October 2020 the highest reported cases of Covid 19 were the Philippines with 2604 cases (2020.10.19), Indonesia 3.373cases (2020.10.19), Singapore 8 cases (2020.10.19), Malaysia 871 cases (2020.10.19), Thailand 5 cases (202010.19), Myanmar 1.180 cases (2020.10.19), Vietnam 6 cases (2020.10.19), Cambodia 2 cases (2020.10.19), was not graph in Timor Leste despite on 19 October 2020 has reported zero case. The graph of the situation is seen in the following Chart below. https://www.worldometers.info/ coronavirus/country/Indonesia, Malaysia, Philipines, Singaporem, Thailand, Vietnam, Cambodia, Brunei, Myanmar/ [4].

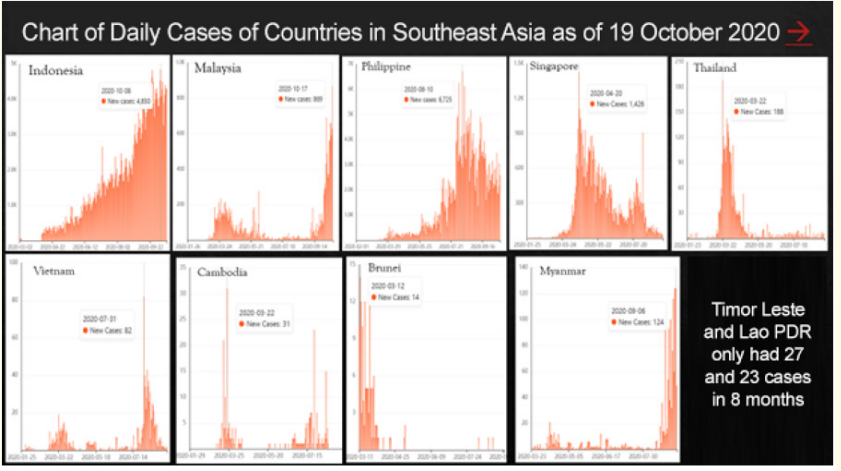

Chart 3 
Increasing the number of cases the faster

In Indonesia there has been a significant increase in the number of cases with the day of transmission from the first reported Covid 19 case in March to October 2020 as follows: In March the CFR from 0 then $>3.5 \%$ even reached 9\%, April 8\% - 9\%, May fell $6 \%$ $-7 \%$, June fell $5 \%-6 \%$, July $4 \%-5 \%$, August 3,9\% -4\%, September $3,7 \%-3,3 \%$, October $3.3 \%-3,1 \%$. This can be seen in graph below.

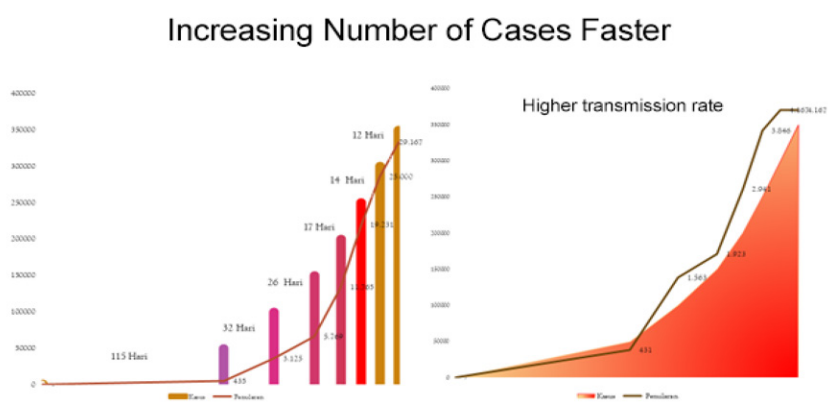

Chart 4

Total deaths between rate and absolute amount in Indonesia

Death reporting has followed WHO guidelines, including probable cases. All of the deaths in Indonesia were laboratory confirmation cases positive for Covid 19. The death rate has shown a decline but the number of deaths has increased consistently. Death rate falls. When the denominator of the number of cases increases, even though $60 \%-65 \%$ of cases are asymptomatic, isolation is carried out until it is finished. Suppose this mortality rate is compared to COVID 19 cases treated with CFR 3.45\% -18.9\%.

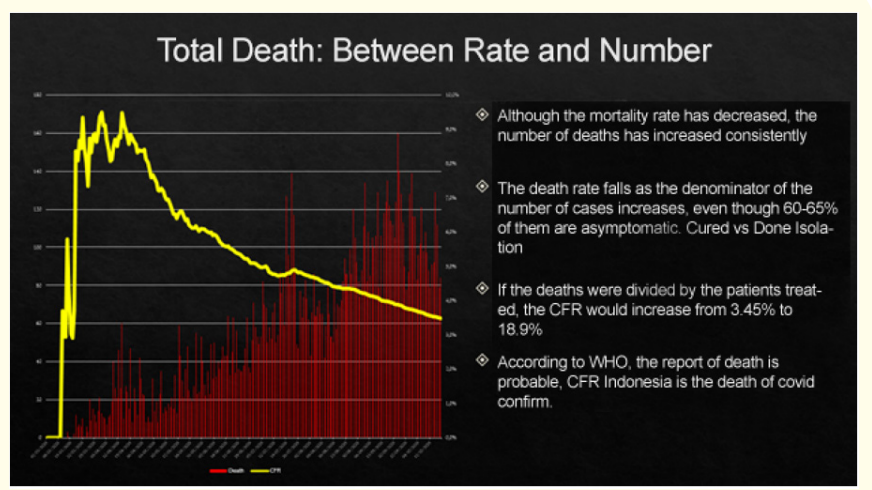

Chart 5
Graph let's playing with statistic in patient on treatment and CFR

The last one month, September-October 2020, the number of patients treated has decreased from 0.16 to $0.04 \%$, while the percentage of patients recovered has increased from $1 \%$ to $80 \%$. The number of patients dying increased by $20 \%$ - 16\%, although the CFR rate was $3 \%-4 \%$. For months without anyone realizing this, even the death of health workers reached 228 people according to the Mitigation Team for the Executive Board of the Indonesian Doctors Association, the Association of Indonesian Dentists Association, and the Indonesian National Nurses on 29 September 2020 quoted from Kompas Com. 28 October 2020 at 19:23 the number of people who died was 254 consisting of 117 doctors, 9 dentists, 85 nurses, 33 midwives, 6 pharmacists, biomedical laboratory technology experts 4 All health workers who died were confirmed and probable Covid 19.

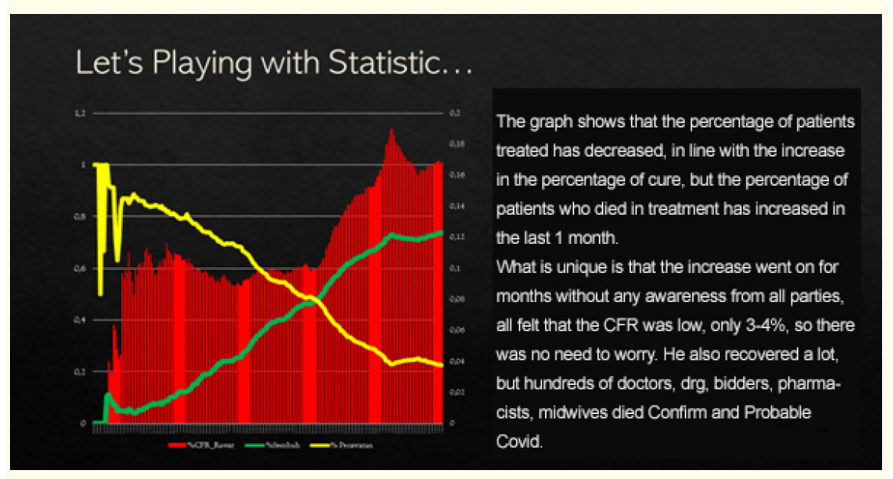

Chart 6: COVID-19 Cluster Case And Its Transmissions In Padang, Banjarmasin And Lampung.

According to the clusters and transmission scenarios, $\geq 80 \%$ of cases and contacts can be seen from the clusters in the cities of Padang, Banjarmasin and Lampung. Epicontact Padang City > 80\% compared to Lampung City, epi contact whether people who are not symptomatic of spreadless, it turns out that it is not proven that people who confirm asymptomatic spreadles can even transmit as many symptomatic cases. This can be seen in the following chart 7 . 


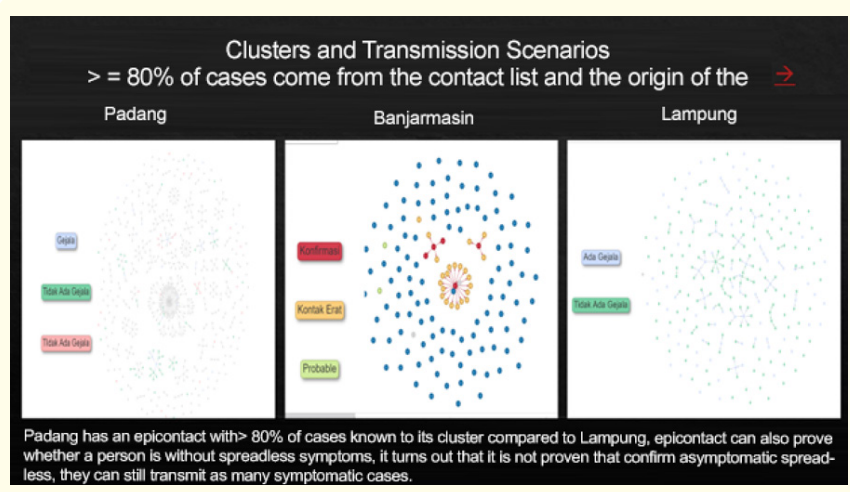

Chart 7

\section{Discussion}

In several countries in the world that have a large population including Indonesia, until now they have not been able to control the Covid 19 cases, while China has quickly resolved the Covid 19 pandemic. Quickly control Covid 19 because China has prepared advanced technology beforehand such as residents being tracked via their cell phones, robots delivering food to patients, like cameras that can recognize faces and body temperatures, there are drones that force quarantine and lockdown. Apart from that it has advanced surveillance which can track their citizens both online and offline. (BBC NEWS Indonesia).

In addition to that success has been researched by Zhang, Ni stated that every day new cases of COVID-19 are confirmed and there is a decline from 27 to 0 in 53 days since the first case of COVID-19 was confirmed in Shanghai on January 20, 2020 [5]. This is due to the Based on Social-Ecological Model program, which is research gathering information for public health strategies from the Shanghai Municipal Health Commission and various Chinese websites.

The base on social-ecological model is as follows

At the social level we focus on reporting systems and strengthening quarantine, public health education through mass media and social media, support for the education system, and support for customs. Other strategies are listed in New Confirmed Cases and Appropriate Public Health Strategies Taken Daily.
Reporting system and strengthening quarantine. Shanghai implements a comprehensive reporting system called "zero reporting" with a focus on 3 groups: (1) people who are undergoing quarantine and observation after returning from the main areas affected by the COVID-19 pandemic; (2) people who return to Shanghai to work in education, property management, logistics and public transportation, medical services, home services, nursing, and labor-intensive factories and enterprises; and (3) people traveling to Shanghai from other area [6].

Transports at the city's 2 international airports picked up people arriving from areas severely affected by the coronavirus pandemic and immediately brought them home for a 14-day quarantine. If a person chooses to be picked up in a private car, the driver and everyone accompanying him must first register with the district official with their name, ID card, contact information, car plate number and destination. Twenty-four hour registration and pick-up service is offered at both Shanghai airports. Staff from the health center, neighborhood committee, police, and volunteer foreign language interpreters visit them at their homes, and they are asked to sign home quarantine pledges. People in Shanghai can also scan QR codes generated by the Shanghai Municipal Transportation Commission in each compartment of a taxi or metro train to register their information. Registration is not mandatory, and the information is only used to quickly locate travelers in the event of possible coronavirus exposure, measures to control the spread of the coronavirus [9].

Public health education through mass media and social media: Offering better risk communication and health education about the outbreak response through mass media and social media campaigns is an important strategy in developing and implementing effective health promotion for the general public. Local health authorities in Shanghai launched various TV programs and online courses to educate the public [7]. In the daily coronavirus press conference hosted by the Shanghai government, 12 medical experts were invited to promote knowledge about health care and disease prevention and control and to ease people's concerns. An online course providing practical steps for cleaning and disinfecting living rooms receives 600,000 spectators simultaneously. The city government also broadcasts a precautionary message about 
the exterior lighting of high-rise buildings, The local Shanghai government uses its official WeChat account (one of China's most popular micro messaging apps) to provide daily updates of the pandemic, including total cases, new confirmed cases, deaths, travel history of confirmed cases, recovered cases, new policies, community intervention, and health promotion. People check dynamic outbreak changes and updates easily and quickly on their phones. The government also offers health promotion and education, such as information to identify early symptoms, personal hygiene in and in public, how to wear masks properly, mental health awareness, rewarded health quizzes, questions and answers with doctors, and specialist recommendations to encourage the public. to engage in self-protection, prevent the spread of the virus to others, and act appropriately in response to outbreaks

\section{Education system support}

According to the Shanghai Municipal Education Commission, 16 all universities and primary and secondary schools in Shanghai launched online education on March 2, 2020, to help control the novel coronavirus pandemic. The integrated teaching schedule is adopted by all primary and secondary schools in Shanghai. Online courses recorded by more than 1000 teachers across the city have been broadcast on TV on 12 channels [5]. Students watching online live classes and replays on TV or online. Students at colleges and universities in Shanghai take online courses delivered by their instructors. Teachers use WeChat to communicate with parents and monitor students' health conditions. For example, Digital Content (indicates that a teacher asks parents to check-in at 9:00 am daily using the calendar function on online application of Health education [5]. Parents reported whether students stayed home and whether they had symptoms, such as fever, cough or difficulty breathing.

\section{Customs support}

According to local authorities, more than 300 customs officials in Shanghai have been dispatched to carry out epidemiological investigations. Passengers are asked to report on a health declaration card whether 2 or more family members or colleagues have fever or other symptoms and whether they have any. taking antipyretic or flu medication in the last 3 days. Customs officers board the plane to check the temperature of the passenger and passenger information that is completed on the health form. Customs officials green label passports to show that the traveler comes from an area with mild epidemic conditions. Those with the red and yellow stickers traveled from the main areas affected by the coronavirus and are required to undergo further screening and examinations. The quarantine zone at the port was upgraded and expanded. Customs clearance readjusted to cope with the mass of passengers. The temperature sensing device has also been upgraded to warn of higher and lower than normal temperatures. The General Administration of Customs of China opened special counters and green lines for the quick cleanup of imported anti epidemic supplies. With proper and effective supervision, officers release inventory after registration to facilitate quick retrieval and minimize clearance time.

Community Level: Community health service centers, in collaboration with local city and neighborhood committees, promote and guide health management for residents in their jurisdictions. Teams of family doctors from each community health center use mobile apps, WeChat, phones, text messages and other channels to actively track the health status of contracted residents. These procedures enable local doctors to understand patient needs, offer guidance in personal health management, and provide health and psychological education services. The Community Health Service Center teaches residents how to take preventive measures, such as cleaning, disinfection, washing hands, wearing masks, and ventilation. Communication is provided via phone calls, posters, flyer banners, 20 community broadcasts, electronic screens, bulletin boards, WeChat, Weibo (China's most popular microblogging Web site), and other forms. Promotion Leaflet about COVID-19 Designed by the Shanghai Health Promotion Center 20 (Left: Tips for Preventing Coronavirus when Using an Escalator. Center: Corona Virus Prevention Tips for Daily Life. Right: Washing Hands to Prevent Coronavirus). The Public Health Service Center also shares health tips and self-protection knowledge, responds immediately to health counseling requested by residents, helps dispel citizens' concerns, ensures that "everyone knows, everyone is acting, and everyone is helping prevent and control COVID-19". These actions create a positive and scientific community atmosphere to achieve epidemic prevention and control. Also, the centers promote a healthy diet, indoor physical activity, personal hygiene habits, and 
ways to maintain a healthy life. Apart from the Public Health Center in Sub District, the environmental committee plays an important role in prevention efforts. Some communities use health care providers to train environmental committee staff on coronavirus prevention and control. Some environmental committees use speakers to broadcast coronavirus prevention and control information to residents at home They also work with property management agencies and volunteers to put up educational informational posters in the community. The ward committee maintains contact with the people who visit or return to Shanghai in 2 ways. First, based on the immigrant resident registration form, the neighborhood committee contacts people who come to Shanghai to understand their travel plans. Second, each ward committee establishes an environmental mutual assistance mechanism whereby residents, neighbors, or family members can report or verify information about their personal or business travel to a list of affected countries or territories [5].

The environmental committee, in collaboration with property management bodies and volunteers, is also active in providing a variety of services to residents who are self-quarantined at home. Members of the environmental committee record the temperature of the self-quarantined occupants and have their health checked by phone or on visits (with social distancing) every day). Meanwhile, the committee also supports the daily lives of residents who undergo self-quarantine by paying attention to emotions, replenishing their daily needs, delivering food or online orders, and collecting and disposing of trash. Under the guidance of epidemic prevention professionals, environmental committees organize community social workers, property management teams, and volunteers to disinfect the community's public areas, such as corridors and playgrounds. Neighborhood committees working with property management agencies have issued permits to quickly differentiate residents from visitors. Hundreds of thousands of workers and volunteers check residents' temperatures, 21 log their movements, and monitor quarantine to prevent the spread of the virus. People from major infected areas both in China and outside China are undergoing a 14-day quarantine.

\section{Organization level}

Seven hospitals in Shanghai were licensed to provide diagnosis and prescriptions online starting February 29, 2020. Prescribed drugs were sent from the hospital pharmacy to the patient's home. Patients can pay registration and treatment fees through online health insurance. These 7 hospitals offered more than 7800 diagnoses and 1450 prescriptions online in the first 2 weeks. Shanghai has also set up a one-stop fever consultation platform consisting of more than 90 doctors from 15 local hospitals who work shifts. Online inquiries are free of charge. The Shanghai Health Commission medical administration department uses information technology to monitor Internet medical service providers and ensure quality and safety. Starting January 16, 2020, many public places in Shanghai will be closed, such as public libraries, community-based cultural activity centers, entertainment facilities, and sports venues. Most tourist attractions have suspended operations, and all major public activities are suspended. Despite event cancellations and closings of cultural venues, the city is providing more online access to arts and recreation. Several museums in Shanghai offer exhibitions, lectures and online forums.

Individual Level: Good personal hygiene habits and proactive prevention are the keys to staying healthy. On January 20, 2020, Dr Nanshan Zhong, a Chinese pulmonologist and leading adviser in dealing with the COVID-19 pandemic crisis, advised the public to wear masks, given the potential signs of human-to-human transmission of COVID-19. The local government advised people to opening windows, washing hands frequently, wearing a mask, maintaining good sleep habits, staying calm, and refraining from screaming or spitting in public. When coughing, a person should look away from others and cover the mouth and nose with a tissue or upper arm. Although there has been a long history for Chinese people sharing a meal, during the COVID-19 outbreak, the Shanghai government launched a campaign to promote the use of chopsticks and serving spoons and not to stir dishes together with chopsticks themselves.

Comparative of implementation covid 19 epidemic control program is specially tracing in China and Indonesia

Indonesian health staf to improving the report system can learn from Shanghai's "zero reporting" mechanism with registration and contact tracing systems. 
- To the general public, we can provide timely updates on disease incidence and prevalence with geographic information, a brief history of the virus for each patient, and testing methods and sites in local public health departments and the Centers for Disease Control and Prevention Websites.

- $\quad$ Press conferences and news reports should be used to shape media plans that move towards the public agenda. When speaking to the public, officials need to know the audience's health literacy level and try to avoid jargon.

- $\quad$ Create or update public health department social media accounts that they can easily follow and read, even on their phones. Synchronize social media content with website content. Monitor social media content to control rumors.

- Develop health-specific applications. For example, a mobile application to track and report the health status and daily needs of people who are quarantined, people who are selfquarantining, or those who have the corona virus but show mild symptoms and choose to stay at home for self-care.

- $\quad$ Providing support for medical and mental health consultations via hotlines is especially important for people who are self-quarantined or quarantined.

\section{Community level}

Indonesia has a diverse ethnic community. Indonesia needs to increase awareness and knowledge about the virus and precautions in each ethnic community in their particular cultural context [3]. For comparison, mainstream communities in the United States, aim for a belief in individualism, autonomy, and independence that is valued and respected [8]. Cultural norms will be enforced in promoting that taking preventive action is not showing weakness or cowardice but heroic action to protect oneself and others through preventive action, such as wearing a mask, undergoing testing, or self-quarantine. For certain minority communities, all information must be translated into different languages to communicate with each community [8]. We used re-translation method, a procedure in which people interpret documents previously translated into the target language back into the source language to check the accuracy of the translation and the legibility of the information.
In addition, it is important to address various cultural norms and increase cultural competence when communicating with diverse communities. The Asian and Hispanic/Latin communities are used as examples in the following text [8]. It is imperative to tackle stigma, racism, discrimination, prejudice and xenophobia against Asian populations, caused by the country of origin where the disease was first discovered and spread. However, there have been many breakthroughs in virus control that have also started in China. In China, wearing a mask is an obligation to contain the spread of the coronavirus. because of the long incubation period. People who carry the virus without knowing it can spread the virus. Wearing a mask is a way to protect not only yourself but also those around you. However, other ethnic groups may not understand the reasons for wearing a mask. Therefore, we need to raise awareness of the values behind wearing masks among the general public and ensure that this is a precautionary measure not only for themselves but also for their communities. In addition, Asian culture values family and community members.

Comparison this research with Djalante research, there was outline gaps and limitations in the responses, based on our rapid analysis of media contents, from government speeches and reports, social and mass media platforms in Indonesia despite 15 regulations were declared to empowerment COVID-19 task forces, acceleration of socialization of COVID-19 Prevention at Provincial and District/City levels. Village Response for COVID-19 and Cash for work in Villages. National Budgeting Policy and the Stability of Budgeting System for COVID-19 Pandemic Disaster and/or Managing Threats for National Economy and/or the Stability Big, Budgeting System, Scale Social Restriction for acceleration COVID-19 Eradication, The result epidemic control program have not been able to break the chain of transmission of Covid 19 and even confirmed cases continue to increase.

Some suggestions on a public health strategy for all communities

\section{Community level recommendations}

- $\quad$ Post posters, banners, electronic screens, or billboards in the community.

- Contact and support homeowners' associations or other community organizations to send flyers and leaflets to residents. 
- Post information on neighborhood or community websites, such as nextdoor.com.

- Create anonymous online communities or groups on social media to provide social support to people who need to be quarantined or self-quarantined at home.

- Create official accounts on various social media used by different ethnic communities (e.g., Facebook, Twitter, Instagram, Snapchat, etc. For mainstream communities; WeChat for Chinese communities.

- $\quad$ People positive has confirmed Covid 19 must be report to head of sub Village, Head of Village, Head of Village, Head Sub District and Public Health Center, to rapid response of tracing, testing, treatment and quarantine close contact and isolation suspect, probable and confirmed cases.

\section{Conclusion}

- $\quad$ Each region needs to learn and take action in response to the novel coronavirus pandemic. This study summarizes an effective public health strategy adopted in Shanghai, China, based on SEM to explain the possibility of developing and improving strategies in Indonesia and other countries that have not succeeded in reducing Covid 19 cases. The differences in the political and social systems between China. Indonesia and other countries need to be aware when reviewing and implementing the steps mentioned above, such as in China.

- We also recognize the limitations of the following studies. We collect information on public health strategies in Indonesia and other countries in the world with a large population in Southeast Asia from official websites and social media accounts and experiences of community health education practitioners. This study may not reflect a comprehensive list of all public health strategies adopted in Indonesia. Other measures taken by health services and pharmacies were not included in our analysis and could contribute to disease control.

- Although China provides general recommendations for health communication measures to prevent and control the spread of COVID-19, also Epidemic Control Program in the
United States could be applied in Indonesia, despite each regions are need to adapt these suggestions to take the activities depend on the characteristics of local situation, political and social systems and practices and preferences.

\section{Implications for policy and practices}

- At the community level, we recommend improving the reporting system with registration and contact tracing; and carry out health communication through different channels to the general public.

- $\quad$ At the community level, we recommend a culturally appropriate approach that suits every community.

- At the organizational level, we recommend various practices for (1) hospitals, public health service unit and other clinics, (2) schools, and (3) other workplaces including companies and agencies.

\section{Bibliography}

1. WHO. World Health Organization. "Coronavirus disease 2019 (COVID-19) situation report” (2020).

2. WHO. WHO Coronavirus Disease (COVID-19) Dashboard. Data last updated: 2020/6/1, 1:55pm CEST (2020).

3. Ministry of Health Indonesia. Coronavirus Disease (COVID-19) Alertness Guideline (Pedoman Kesiapsiagaan Menghadapi Coronavirus Disease (COVID-19). Jakarta: Ministry of Health Indonesia (2020).

4. https://www.worldometers.info/coronavirus/country/ myanmar/

5. Zhang N., et al. "COVID-19 Prevention and Control Public Health Strategies in Shanghai, China”. JPHMP 26.4 (2020).

6. Shanghai Municipal Education Commission. Universities, primary and secondary schools in Shanghai will launch online courses from March (2020).

7. Shanghai Municipal Education Commission. "Classroom in the Air" online education for primary and middle school students has been launched (2020). 
8. Oaten M., et al. "Disease avoidance as a functional basis for stigmatization". Philosophical Transactions of the Royal Society 366.1583 (2011).

9. Djalante R., et al. "Review and analysis of current responses to COVID-19 in Indonesia: Period of January to March 2020". Progress in Disaster Science (2020).

\section{Assets from publication with us}

- Prompt Acknowledgement after receiving the article

- Thorough Double blinded peer review

- Rapid Publication

- Issue of Publication Certificate

- High visibility of your Published work

Website: www.actascientific.com/

Submit Article: www.actascientific.com/submission.php

Email us: editor@actascientific.com

Contact us: +919182824667 